\title{
Medium Optimization for Production of Beauveriabassiana BNBCRC Spores from Biohydrogen Effluent of Palm Oil Mill Using Taguchi Design
}

\author{
Wanida Petlamul and Poonsuk Prasertsan
}

\begin{abstract}
Beauveria bassiana is an efficient entomopathogenic fungus for biological control. Optimization on medium for the production of $B$. bassiana BNBCRC spores in biohydrogen effluent (BHE)-based liquid culture was investigated using Taguchi design. The effects of inorganic and organic nitrogen, trace element as well as the dilution rate of BHE: distilled water were studied in BHE-based composition. The highest spore concentration of $B$. bassiana BNBCRC was $4.46 \times 10^{8}$ spores $\mathrm{mL}^{-1}$ in the diluted BHE-based medium containing $3.60 \mathrm{~g}$ $\mathrm{L}^{-1} \mathrm{KNO}_{3}, 4.55 \mathrm{~g} \mathrm{~L}^{-1}$ yeast extract and $0.50 \mathrm{~g} \mathrm{~L}^{-1} \mathrm{CaCl}_{2}$ under the optimal dilution rate of 60:40. The determination coefficient $\left(\mathbf{R}^{2}\right)$ was 0.99 , which ensure an adequate credibility of the model.
\end{abstract}

Index Terms-Beauveriabassiana, biohydrogen effluent, optimization, taguchi design.

\section{INTRODUCTION}

Use of Beauveriabassiana for the biological control of pest and disease vector insects is interesting as it is an effective method and environmentally friendly. Recently, the full potential and many advantages of this practice reached application on a commercial scale [1]. Mass production processes directly influence the cost, shelf life, virulence and field efficacy of fungal products. Therefore, the production process must be low-cost and gave high yield [2]. The type of process used depends on the fungal strain, target pest, environment, formulation, application strategies, and desired end product.

The nutrient composition of the production medium has a significant impact on the attributes of the resulting propagules. Optimization of production procedures should be designed to address this factor [3]. The high cost of culture medium is an obstacle in the commercial application [4]. Moreover, getting large quantity of this fungus would support distribution to farmers for biological control in the field.

Palm oil mill effluent (POME) is known to have various substrates that could be used by various microorganisms [5], [6] including hydrogen-producing bacteria. Biohydrogen effluent (BHE) was obtained from hydrogen production process from POME and contains other substrates especially volatile fatty acid (VFA). This resulted in the high content of chemical oxygen demand(COD) and biochemical oxygen

Manuscript received October 11, 2013; revised December 12, 2013. This work was financially supported by a scholarship from the Office of the Higher Education Commissionto Ms. Wanida Petlamul.under the CHE-PhD Program, and Graduate School of Prince of Songkla University.

The authors are with the Department of Industrial Biotechnology Faculty of Agro-Industry, Prince of Songkla University, Hatyai, Songkhla 90112, Thailand (e-mail: wanipet@hotmail.com,poonsuk918@yahoo.com). demand (BOD) values that still need further treatment before being discharged to environment [7]. As there are no the best tested factors for bringing out spore production, both nutrients and physico-parameters of the cultivation can have a huge effect on spore production [8]. In addition, the use of a good reliable statistical model is essential to develop better strategies for the optimization of the cultivation [9]. Seyedeh et al. (2007) [10] applied Taguchi design for protease production by Bacillus clausii and reported that this experimental design provides basic information to improve the efficiency of protease production and also supported the analysis of the main effect of each component. A previous study of evaluation of virulence, germination rate, spore production, radial growth and enzyme activity of entomopathogenic fungi was presented on B.bassiana strain BNBCRC [11], so it would be supported for production in this study. In this study, BHE was used as an alternative substrate for the mass production of B. Bassiana spores as a component of integrated pest management. BHE is an inexpensive source, and its use for production of value-added product can provide an alternative approach for palm oil mill. The goal of this research was to evaluate and optimize BHE for spore production of B.bassiana in liquid fermentation using Taguchi design.

\section{MATERIALS AND METHODS}

\section{A. Microorganism and Inoculum Preparation}

Spore inoculum of B. bassiana BNBCRC was prepared by cultivation on the Czapek Dox Agar (CDA) plates at room temperature $\left(30 \pm 2^{\circ} \mathrm{C}\right)$ for 7 days. Sterile distilled water $(10$ $\mathrm{mL}$ ) was added on the fungal colonies. The spore suspensions were prepared by scraping using a spreader and gently probing the surface with the tip of a Pasture pipette [12]. The spore suspension was mixed thoroughly using a vortex and diluted to obtain a suspension of $1 \times 10^{6}$ spores $\mathrm{mL}^{-1}$. This was considered as the standard inoculums for all experiments and was used to inoculate the fermentation medium immediately.

\section{B. Characteristics of Biohydrogen Effluent (BHE)}

The raw BHE used as liquid substrate for this experiment was obtained from biohydrogen production process of the Biohythane Project at Prince of Songkla University. The raw BHE was measured for $\mathrm{pH}$ and determined for COD, and total Kjeldahl nitrogen (TKN) in accordance with the procedures described in the Standard Methods [13]. Soluble metabolites such as acetic acid, butyric acid, propionic acid, butanol, ethanol, glucose, arabinose and xylose were determined by Gas Chromatography equipped with FID. The procedure was 
as described by Suwansaard [14]. The raw BHE was kept at 0 ${ }^{\circ} \mathrm{C}-4^{\circ} \mathrm{C}$ until used.

\section{Liquid Fermentation of BHE}

All fermentations using raw BHE as the carbon source were carried out at room temperature $\left(30 \pm 2^{\circ} \mathrm{C}\right)$ for 7 days under various parameters such as dilution rate, inorganic and organic nitrogen as well as trace element. Each factor was tested in the BHE, as described in the following parts of this paper. The amount of inorganic and organic nitrogen used for spore production was calculated based on nitrogen content of the raw BHE as previously determined.

Determination of spore yield, spore suspension in three replications was prepared by taking $3 \mathrm{~mL}$ sample of the culture broth, in a sterilized test tube containing $3 \mathrm{~mL}$ sterile $0.05 \%$ (v/v) Tween 80 and mixed thoroughly by using the vortex. After incubation for 7 days, the number of spores was counted with a hemocytometer under $400 \times$ magnifications in a bright field microscopy. The results were the means of triplicate determination of two independent samples. The determination of spore productivity was calculated from the values of the productivity obtained and the time (days) in which each isolate took to produce spores [15].

\section{Taguchi Designand Data Analysis}

The aim of using Taguchi design approach of orthogonal array experimental design focusing on finding the main effects represents the output response was to increase the production of spore in order to test, in further studies. This evaluation of nutrient addition was performed by using Taguchi design as in Table I, and then identified components of the media that had significant effects on spore production.

Few works have reported the optimization for spore production in liquid fermentation from lignocellulosic by-product by using statistical model. Most of these investigations are concerned with the influence of medium component in culture media or in several grains [16].

Inorganic (urea, $\mathrm{KNO}_{3}, \mathrm{NH}_{4} \mathrm{NO}_{3}$ and $\mathrm{NaNO}_{3}$ ) and organic (yeast extract, peptone, beef extract and skim milk)nitrogen sources, trace elements $\left(\mathrm{CuSO}_{4}, \mathrm{MgSO}_{4}, \mathrm{MnSO}_{4}\right.$ and $\left.\mathrm{CaCl}_{2}\right)$ and dilution ratio were varied in different concentrations according to Taguchi design(Table III). These nitrogen sources differ in the percentage of nitrogen content $(\% \mathrm{w} / \mathrm{w})$, and the total required concentration $\left(\mathrm{g} \mathrm{L}^{-1}\right)$ from each nitrogen source was calculated (Table II) in order to equalize the total nitrogen content $\left(0.5 \mathrm{~g} \mathrm{~L}^{-1}\right)$. In this liquid fermentation, the BHE-based medium composition had theCOD: TKN (C: $\mathrm{N}$ ) ratio of56.58 (Table III). Therefore, it was adjusted to 29.63 by adding either inorganic or organic nitrogen source to reach the total nitrogen of $1.00 \mathrm{~g} \mathrm{~L}^{-1}$. These nutrients were mixed with raw BHE as a basal medium then were put into each $250 \mathrm{ml}$ flask containing total volume 100 $\mathrm{mL}$; the flasks were plugged loosely with a stopper of cotton wool and sterilized $\left(121{ }^{\circ} \mathrm{C}, 15 \mathrm{~min}\right)$. Organic nitrogen sources were sterilized separately, and urea was sterilized by filtration. After cooling to room temperature $10 \mathrm{~mL}$ spore suspension $\left(1 \times 10^{6}\right.$ spores $\left.\mathrm{mL}^{-1}\right)$ of $B$. bassiana BNBCRC was inoculated and incubated at room temperature $\left(30 \pm 2^{\circ} \mathrm{C}\right)$. The contents were mixed thoroughly by shaking at $180 \mathrm{rpm}$. The spore production of $B$. bassiana BNBCRC was evaluated after incubation for 7 days.
TABLE I: FERMENTATION BY TAGUCHI DESIGN FOR SPORE PRODUCTION OF BEAUVERIA BASSIANA BNBCRC

\begin{tabular}{|c|c|c|c|c|}
\hline Factors & Level 1 & Level 2 & Level 3 & Level 4 \\
\hline In. Nitrogen & Urea & $\mathrm{KNO}_{3}$ & $\mathrm{NH}_{4} \mathrm{NO}_{3}$ & $\mathrm{NaNO}_{3}$ \\
\hline Or.Nitrogen & Yeast extract & Peptone & Beef extract & $\begin{array}{l}\text { Skim } \\
\text { milk }\end{array}$ \\
\hline $\begin{array}{l}\text { Trace } \\
\text { element }\end{array}$ & $\mathrm{CuSO}_{4}$ & $\mathrm{MgSO}_{4}$ & $\mathrm{MnSO}_{4}$ & $\mathrm{CaCl}_{2}$ \\
\hline $\begin{array}{l}\text { Dilution } \\
\text { rate }\end{array}$ & 100:0 & 80: 20 & 60: 40 & 40: 60 \\
\hline
\end{tabular}

TABLE II: THE AMOUNT OF INORGANIC AND ORGANIC NITROGEN USING TAGUCHI DESIGN USED FOR SPORE PRODUCTION OF BEAUVERIA BASSIANA BNBCRC IN LIQUID FERMENTATION

\begin{tabular}{cccc}
\hline \hline $\begin{array}{c}\text { Nitrogen sources } \\
\left(\mathrm{g} \mathrm{L}^{-1}\right)\end{array}$ & $\begin{array}{c}\text { Nitrogen content } \\
(\% \mathrm{w} / \mathrm{w})\end{array}$ & $\begin{array}{c}\text { Total required } \\
\left(\mathrm{g} \mathrm{L}^{-1}\right)\end{array}$ & $\begin{array}{c}\text { Total N } \\
\left(\mathrm{g} \mathrm{L}^{-1}\right)\end{array}$ \\
\hline Urea & 46.7 & 1.07 & 0.5 \\
$\mathrm{KNO}_{3}$ & 13.9 & 3.60 & 0.5 \\
$\mathrm{NH}_{4} \mathrm{NO}_{3}$ & 35.0 & 1.43 & 0.5 \\
$\mathrm{NaNO}_{3}$ & 16.5 & 3.03 & 0.5 \\
Yeast extract & 11.0 & 4.55 & 0.5 \\
Peptone & 15.4 & 3.25 & 0.5 \\
Beef extract & 12.4 & 4.03 & 0.5 \\
Skim milk & 8.6 & 5.81 & 0.5 \\
\hline \hline
\end{tabular}

TABLE III: BIOHYDROGEN EFFLUENT CHARACTERISTICS FROM HYDROGEN PRODUCTION PROCESSES

\begin{tabular}{cc}
\hline \hline Parameters & Biohydrogen effluent \\
\hline COD $\left(\mathrm{mg} \mathrm{L}^{-1}\right)$ & 62,236 \\
Acetic acid $\left(\mathrm{mg} \mathrm{L}^{-1}\right)$ & 7,340 \\
Butyric acid $\left(\mathrm{mg} \mathrm{L}^{-1}\right)$ & 4,654 \\
Butanol $\left(\mathrm{mg} \mathrm{L}^{-1}\right)$ & 108 \\
Ethanol $\left(\mathrm{mg} \mathrm{L}^{-1}\right)$ & 572 \\
Propionic acid (mg L & 423 \\
Glucose $\left(\mathrm{mg} \mathrm{L}^{-1}\right)$ & 589 \\
Xylose $\left(\mathrm{mg} \mathrm{L}^{-1}\right)$ & 2,085 \\
Arabinose $\left(\mathrm{mg} \mathrm{L}^{-1}\right)$ & 657 \\
TKN $(\%)$ & 1.1 \\
$\mathrm{pH}$ & 5.42 \\
COD:TKN $(\mathrm{C:} \mathrm{N})$ & 56.58 \\
\hline \hline
\end{tabular}

\section{E. Scanning Electron Microscopy}

Growth of B. bassiana BNBCRC on the BHE particles was characterized by using an electron microscope (JEOL JSM $5800 \mathrm{LV}$, Japan). The fermented sample (168 h) was dried and mounted on a brass stud followed by a mild gold coating $(100 \AA)$ and was subjected to electron microscopy at an accelerating voltage of $15 \mathrm{kV}$.

\section{RESUlTS AND DisCUSSIONS}

\section{A. Characteristics of Raw Biohydrogen Effluent (BHE)}

Characteristics of the raw BHE taken from biohydrogen production process were shown in Table III. It was found to contain high organic matter (COD value of 62,236 $\mathrm{mg} \mathrm{L}^{-1}$ ), low nitrogen content $(1.1 \% \mathrm{TKN})$, and low $\mathrm{pH}(5.42)$. The high organic matter content is due to the presence of different sugars such as arabinose, xylose and glucose at the concentrations of $657,2,085$ and $589 \mathrm{mg} \mathrm{L}^{-1}$, respectively. Moreover, BHE had volatile fatty acid such as acetic, butyric and propionic acid. Therefore, BHE can be a good source of non-toxic nutrients for microorganisms and non-toxic. In addition, the ratio of $\mathrm{C}: \mathrm{N}$ in BHE was calculated to be 29.63 which is suitable for microbial growth including entomopathogenic fungus $B$. bassiana. Since BHEis non-toxic as no chemical added in the oil extraction process, it is a good source of nutrients for microorganisms. 


\section{B. Optimization of Nitrogen Sourcesand Trace Elements Using Taguchi Design}

Taguchi designis very useful for estimating main effect factors from a list of candidate factors, and deletion to estimate certain interaction. The results showed that $B$. bassiana BNBCRC could grow and produce spores in all experiments. The highest spore concentration was obtained in run $7\left(4.46 \times 10^{8}\right.$ spores $\left.\mathrm{mL}^{-1}\right)$ with the supplementation of urea, peptone and $\mathrm{MgSO}_{4}$ in the $\mathrm{BHE}$ and the optimum dilution rate at 60: 40(Table IV).

TABLE IV: LEVELS OF FOUR FACTORS, APPLIED IN EACH OF 16 TRAILS, AND OBTAINED RESULTS

\begin{tabular}{ccccccc}
\hline \hline \multicolumn{6}{c}{$\begin{array}{c}\text { Inorganic Organic } \\
\text { Run }\end{array}$} & \multicolumn{3}{c}{$\begin{array}{c}\text { Dilution } \\
\text { Nitrogen Nitrogen }\end{array}$} & $\begin{array}{c}8 \\
\text { Actual } 10^{8}\end{array}$ & $\begin{array}{c}\text { Predict } 10^{-1} \\
\text { ratio }\end{array}$ \\
\hline 1 & 1 & 1 & 1 & 1 & 4.20 & 4.03 \\
2 & 2 & 2 & 2 & 2 & 3.18 & 3.28 \\
3 & 3 & 3 & 2 & 3 & 1.21 & 0.95 \\
4 & 1 & 3 & 4 & 4 & 2.37 & 2.46 \\
5 & 4 & 3 & 3 & 1 & 1.63 & 1.81 \\
6 & 3 & 4 & 4 & 2 & 1.56 & 1.65 \\
7 & 2 & 1 & 4 & 3 & 4.46 & 4.55 \\
8 & 4 & 4 & 1 & 4 & 1.53 & 1.55 \\
9 & 2 & 3 & 1 & 1 & 2.58 & 2.57 \\
10 & 4 & 2 & 4 & 2 & 2.55 & 2.28 \\
11 & 3 & 2 & 1 & 3 & 1.36 & 1.53 \\
12 & 2 & 4 & 3 & 4 & 3.48 & 3.29 \\
13 & 1 & 2 & 3 & 1 & 3.82 & 3.82 \\
14 & 1 & 4 & 2 & 2 & 2.92 & 3.00 \\
15 & 3 & 1 & 3 & 3 & 2.71 & 2.71 \\
16 & 4 & 1 & 2 & 4 & 2.63 & 2.71 \\
\hline \hline
\end{tabular}

The results of statistical analysis showed that the highest percentage contribution of $49.33 \%$ (Table V) was obtained from inorganic nitrogen source. Therefore, inorganic nitrogen source was the most important factor for spore production of $B$. bassiana BNBCRC in this liquid fermentation. $\mathrm{KNO}_{3}$ was the preferred inorganic nitrogen for spore production of $B$. bassiana BNBCRC. Yeast extract also supported to increase the spores. Pham et al. (2009) [17], demonstrated that, among the five different carbon sources evaluated from traditional optimization, the highest level of spore production was observed when corn meal was used as a carbon source in the medium containing $2 \%$ peptone. This result demonstrated that the optimal $\mathrm{C}: \mathrm{N}$ ratio for spore production of $B$. bassiana BNBCRC was at 29.63 in the BHE-based liquid culture (with the initial $\mathrm{C}: \mathrm{N}$ ratio of56.58)after adding urea (1.07 $\left.\mathrm{g} \mathrm{L}^{-1}\right)$ and peptone $\left(3.25 \mathrm{~g} \mathrm{~L}^{-1}\right)$ in total concentration of $1.00 \mathrm{~g} \mathrm{~L}^{-1}$ (as in Table II). The optimum C:N ratio for B. bassiana BNBCRC was about 3 times higher than those for B. bassiana (C: $\mathrm{N}$ ratio of 10: 1 , using sucrose and casamino acid)[2], and Metarhiziumanisopliae SQZ-1-21 (C: N ratio of 10:1 and 20:1) [18]. However, it was 18.5 times higher than that for Metarhizium flavoviride Mf189 based on sucrose and brewer's yeast (with a C: N ratio of 1.6) [19]. This indicates that the optimal $\mathrm{C}$ : $\mathrm{N}$ ratio differed with different fungal strains.

In this regard, Taguchi approach for screening medium component is a good reliable statistical model. Taguchi design involves independent variables (factors) over region of interest (levels) by identifying the individual factors establishing the relationship between variables and also the performance at the optimum levels. In this case, the least important factor was the levels of dilution rate. Therefore, the analysis of variance, ANOVA, for the response of spore production was carried out according to the contributed factors more than $10 \%$ as suggested by Taguchi design [20]. In this fermentation, the ANOVA of spore production has a model $\mathrm{F}$ value at 42.06 and the coefficient of $R^{2}$ at 0.99 showing that this model was significant.

TABLE V: NOVA FOR SELECTED FACTORIAL MODEL IN LIQUID FERMENTATION FROM TAGUCHI METHOD DESIGN

\begin{tabular}{ccccccc}
\hline \hline Source & DF & $\begin{array}{c}\text { Sum of } \\
\text { Squares }\end{array}$ & $\begin{array}{c}\text { Mean } \\
\text { Square }\end{array}$ & $\begin{array}{c}F \\
\text { Value }\end{array}$ & Prob> F & $\begin{array}{c}\% \\
\text { Contribution }\end{array}$ \\
\hline Model & 3 & 13.38 & 1.11 & 42.06 & 0.0052 & significant \\
Inorganic nitrogen & 3 & 4.25 & 1.42 & 53.40 & 0.0042 & 49.33 \\
Organic Nitrogen & 3 & 5.03 & 1.68 & 63.31 & 0.0033 & 32.80 \\
Trace element & 3 & 1.72 & 0.57 & 21.60 & 0.0156 & 10.18 \\
Dilutionrate & 3 & 0.96 & 0.32 & 12.02 & 0.0353 & \\
Residual & 15 & 0.08 & 0.02 & & & \\
CV & & & & 6.03 & & \\
Std. Dev. & & & & 0.16 & & \\
$\mathrm{R}^{2}$ & & & & 0.994 & & \\
\hline \hline
\end{tabular}

The last column of the ANOVA indicated the influence of each factor in spore production of Beauveriabassiana BNBCRC. The analysis of these experimental data indicated that factors such as nitrogen source, nitrogen supplement, trace element, and dilution ratio play significant roles in spore production, respectively. It was apparent that the type of nitrogen source was the most significant factor for spore production and this factor gave the maximum sum of squares (S) and maximum percentage influence (49.33) but type of dilution rate has no significant effect. Other/error refers to experimental error, DF degrees of freedom

These results suggest that the different combinations of carbon and nitrogen sources led to different spore yields. $\mathrm{KNO}_{3}$ and yeast extract were the most effective to promote spore production of $B$. bassiana than $\mathrm{NaNO}_{3}$ and $\mathrm{NH}_{4} \mathrm{NO}_{3}$ in liquid state. This fungal strain can slightly utilize $\mathrm{NaNO}_{3}$ and $\mathrm{NH}_{4} \mathrm{NO}_{3}$. The failure of some fungi to use ammonia is due to the toxicity of $\mathrm{pH}$ changing in solution by the release of the proton into the medium when microorganism uses ammonium. The form of the supplied nitrogen and $\mathrm{pH}$ of the media are important criteria for fungal growth. Utilization of ammonium salts $\left[\mathrm{NH}_{4} \mathrm{Cl}, \mathrm{NH}_{4} \mathrm{NO}_{3},\left(\mathrm{NH}_{4}\right)_{2} \mathrm{SO}_{4}\right]$ has been reported to induce a rapid drop in $\mathrm{pH}$; consequently, the mycelial growth was inhibited [21]. But, in case of urea, $\mathrm{pH}$ remains stable and hence higher spore numbers were obtained with these four nitrogen sources as compared to the high concentration of ammoniumnitrate and sodiumnitrate. This result was different from Sabbour et al. (2011) [22] which reported that $\mathrm{Ca}\left(\mathrm{NO}_{3}\right)_{2}$ was the best nitrogen source for growth of $B$. bassiana followed by glycine, $\mathrm{NaNO}_{3}$ and $\mathrm{NH}_{4} \mathrm{NO}_{3}$. Yeast extract, has been recognized as a major source of vitamin B-complex, vitamins as a substrate in a medium's formulation, supplies not only vitamins, but also protein as well as carbohydrates and some micronutrients.

\section{Scanning Electron Microscopy}

Visual observation of the growing culture by SEM showed that $B$. bassianagrew very well in BHE-based medium after $168 \mathrm{~h}$ incubation (Fig. 1 a) ), when compared with the 
medium without the fungal strain (Fig. 1 b) ). The SEM photograph showed a mat like knitted structure in which mycelia were embedded in the BHE particles.

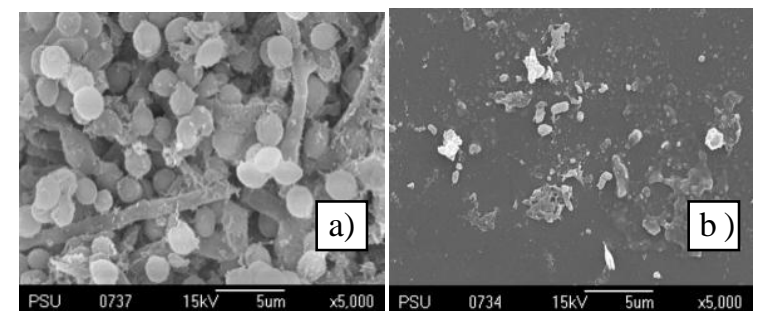

Fig. 1. SEM photograph showing the growth of Beauveriabassiana BNBCRC a) and biohydrogen effluent without Beauveriabassiana BNBCRC addition $\mathrm{b}$ ) after incubation for $168 \mathrm{~h}$ at room temperature.

\section{CONCLUSION}

This study provide information not only for spore production of $B$. bassiana BNBCRC, but also serves as an example for the application of statistical techniques for choosing the optimized conditions depending on the response of interest such as spore production.

Taguchi design was successfully applied to test the relative importance of medium components and environmental factors on spore production. Under the optimum medium condition, the highest spore production of $4.46 \times 10^{8}$ spores $\mathrm{mL}^{-1}$ in BHE was obtained with the addition of $3.60 \mathrm{~g}$ $\mathrm{L}^{-1} \mathrm{KNO}_{3}, 4.55 \mathrm{~g} \mathrm{~L}^{-1}$ yeast extract and $0.50 \mathrm{~g} \mathrm{~L}^{-1} \mathrm{CaCl}_{2}$ in the optimal dilution ratio of 60:40 under the incubation temperature at $30^{\circ} \mathrm{C}$.

\section{ACKNOWLEDGMENT}

The authors gratefully acknowledge the Office of the Higher Education Commission for grant made to support for this work to Miss Wanida Petlamul under the CHE-PhD Scholarship Program, and the Office of the Higher Education Research Promotion and Graduate School of Prince of Songkla University.

\section{REFERENCES}

[1] R. A. Cloyd, "The entomopathogenic fungus Metarhiziumanisopliae," Midwest Biological Control News, 2008, vol. 6, no. 7.

[2] F. E. Vega, M. A. Jackson, G. Mercandier, and T. J. Poprawski, "The impact of nutrition on spore yields for various fungal entomopathogens in liquid culture," World Journal of Dairy Science, vol. 90, pp. 2141-2146, 2003.

[3] N. Aktas, I. H. Boyaci, M. Mutlu, and A. Tanyolac, "Optimization of lactose utilization in deproteinated whey by Kluyveromycesmarxianus using response surface methodology (RSM)," Bioresource Technology, vol.9 7, pp. 2252-2259, 2006

[4] F. Ma, S. Li, W. Jin, and J. Yang, "Present condition and trend of studied on microbial flocculant," Industrial Wastewater, vol. 33, pp. 7-9, 2002.

[5] P. Pechsuth, P. Prasertsan, and M. Ukita, "High rate anaerobic treatment of palm oil mill effluent," Songklanakarin J. Sci. Technol. (Supplement), vol. 23, pp. 779-787, 2001.

[6] P. Prasertsan, A. H. Kittikun, and S. Chantaphaso, "Comparison on decolorization of palm oil mill effluent by biological, chemical and physical methods," Songklanakarin J. Sci. Technol. (Supplement), vol. 23, pp. 807-819, 2001

[7] C. Xin, L. Yin, D. Guocheng, and C. Jian, "Application of response surface methodology in medium optimization for spore production of Coniothyriumminitans in solid-state fermentation," World Journal Microbiology and Biotechnology, vol. 21, pp. 593-599, 2005.

[8] J. Fargues, N. Smith, C. Vidal, A. Vey, F. Vega, and G. Mercadier, "Effect of liquid culture media on morphology, growth, propagule production, and pathogenic activity of the hyphomycete
Metarhiziumflavoviridae," Mycopathologia, vol. 154, pp. 127-138, 2002.

[9] A. E. Ghaly, M. Kamal, and L. R. Correia, "Kinetic modeling of continuous submerged fermentation of cheese whey for single cell protein production," Bioresource Technol., vol. 96, pp. 1143 -1152, 2005.

[10] F. G. O. Seyedeh, T. Fatemeh, Y. Bagher, and E. Fereshteh, "Enhancement of alkaline protease production by Bacillus clausii using Taguchi experimental design," African J Biotechnol, vol. 6, pp. 2559-2564, 2007.

[11] P. Wanida and P. Poonsuk, "Evaluation of strains of Metarhiziumanisopliae and Beauveriabassiana against Spodopteralitura on the basis of their virulence, germination rate, conidia production, radial growth and enzyme activity," Mycobiology, vol. 40, pp. 111-116, 2012.

[12] D. A. Santos and J. S. Hamdan, "Evaluation of broth microdilution antifungal susceptibility testing conditions for Trichophytonrubrum," Journal of Clinical Microbiology, vol.43, pp. 1917-1920, 2005.

[13] APHA, "Standard method of the examination of the water and wastewater," American Public Health Association, $19^{\text {th }}$ Ed., USA: Wastington DC., pp. 1220, 1998.

[14] M. Suwansaard, "Production of hydrogen and 5-aminolevulinic acid by photosynthetic bacteria from palm oil mill effluent," Ph.D. dissertation, Dept. Agro-Industry, Prince of SongklaUniv., Songkhla, Thailand, 2010.

[15] M. L. G. Simões et al., "Evaluation of Trichodermas for the Biocontrol of Moniliophthoraperniciosa Subgroup 1441," Journal of Biology and life Science, vol. 3, pp. 18-36, 2012.

[16] L. Ibrahim, T. M. Butt, and P. Jenkinson, "Effect of artificial culture media on germination, growth, virulence and surface properties of entomopathogenichyphomycete Metarhiziumanisopliae," Mycological Resource, vol. 106, pp. 705-715, 2002.

[17] T. A. Pham, J. J. Kim, S. G. Kim, and K. Kim, "Production of blastospore of entomopathogenicBeauveriabassiana in a submerged batch culture," Mycobiology, vol. 37, pp. 218-224, 2009.

[18] L. Gao, M. H. Sun, X. Z. Lui, and C. S. Yong, "Effects of carbon concentration and carbon to nitrogen ratio on the growth and sporulation of several biocontrol fungi," Mycological Resource, vol 111, pp. 787-92, 2007.

[19] N. Issaly, H. Chauveau, F. Aglevor, J. Fergues, and A. Durand, "Influence of nutrient, $\mathrm{pH}$ and dissolved oxygen on the production of Metarhiziumflavoviride Mf189 blastospores in submerged batch culture," Process Biochem, vol. 40, pp. 1425-1431, 2005.

[20] C. K. Venil and P. Lakshmanaperumalsamy, "Taguchi experimental design for medium optimization for enhanced protease production by Bacillus subtilis HB04 e-J," Science and Technology, vol. 4, pp. 1-10, 2009.

[21] T. Yamanaka, "Utilization of inorganic and organic nitrogen in pure cultures by saprotrophic and ectomycorrhizal fungi producing sporophores on urea-treated forest floor," Mycological Resource, vol. 103, pp. 811-816, 1999.

[22] M. M. Sabbour, M. Ragei, and A. A.-E. Rahman, "Effect of some ecological factors on the growth of Beauveriabassiana and Paecilomycesfumosoroseusagainst corn borers," Australian Journal Basic and Applied Science, vol. 11, pp. 228-235, 2011.

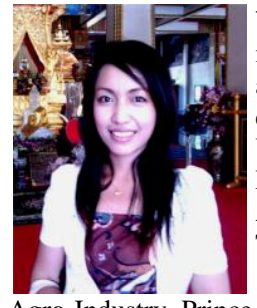

Wanida Petlamul was born in P. Songkhla, Thailand in 1983. She earned her bachelor degree in agricultural science and obtained her master degree in entomological science from Prince of Songkla University, Thailand in 2005 and 2009, respectively. Now she is Ph.D. student in biotechnology, Dept Agro-Industry, Prince of Songkla University, Thailand.

Wanida Petlamul is a full time student at Dept. Agro-Industry, Prince of Songkla University, Thailand under the CHE-PhD Scholarship Program, to be a lecturer at Songkhla RajabhatUniversity after graduation. Some of her publication are about biological control focusing on entomopathogenic fungi as follow; 1) Petlamul W, Prasertsan P. 2012. Evaluation of strains of Metarhiziumanisopliae and Beauveriabassiana against Spodopteralitura on the basis of their virulence, germination rate, conidia production, radial growth and enzyme activity. Mycobiology; 40:111-116. 2) Petlamul W, Prasertsan P. 2012. Mass Production of BeauveriabassisnaUsimg Decanter Cake from Pal Oil Mill. Try out in Research of Prince of Songkla University; 4: 101-103. 3) Petlamul W, Prasertsan P. 2013. Medium Optimization for Production of Entomopathogenic Fungi Beauveriabassiana BNBCRC Spores for Biocontrol Using Decanter Cake from Palm Oil Mill Using Response Surface Methodology. (Submitted-Revised in J. the Korean Society for Applied Biological Chemistry). 